\title{
Waterless purification using oil palm biomass-derived bioadsorbent improved the quality of biodiesel from waste cooking oil
}

\begin{abstract}
The utilization of adsorbents produced from biomass for tertiary treatment of industrial wastes has gained much interest compared to the conventional methods such as flocculation and coagulation. In the present study, a bioadsorbent produced from pressed-shredded oil palm empty fruit bunch was used to remove impurities from crude biodiesel derived from waste cooking oil. The purification process was performed using 1 to $5 \mathrm{wt} \%$ bioadsorbent loadings under continuous stirring at $500 \mathrm{rpm}$ for $1 \mathrm{~h}$. After purification using $5 \mathrm{wt} \%$ of bioadsorbent loading, $89.7 \%$ of residual methanol, $81.7 \%$ of water, $36.7 \%$ of free fatty acid and $98.6 \%$ of potassium were successfully removed. This met the European Biodiesel Standard (EN14214). In comparison to commercial adsorbents and the water washing method, purification using the oil palm empty fruit bunch derived bioadsorbent resulted in higher removal of free fatty acids, potassium, water impurities and a smaller loss of fatty acid methyl esters. It was found that the use of the bioadsorbent improved the biodiesel quality besides its benefits of ease of operations and avoidance of waste water production.
\end{abstract}

Keyword: Biodiesel; Purification; Biomass; Bioadsorbent; Waste cooking oil 